\title{
Thrombosis and bleeding outcomes in the treatment of cerebral venous thrombosis in cancer
}

Nadia I Abelhad ${ }^{1}$, Wei Qiao ${ }^{2}$, Naveen Garg ${ }^{3}$ and Cristhiam M. Rojas-Hernandez ${ }^{4^{*}}$

\begin{abstract}
Background: There is a need for clinical outcome data of cerebral venous thrombosis (CVT) in cancer patients. We examined the recanalization, thrombosis recurrence and major bleeding during CVT treatment in a cancer exclusive adult population.

Methods: We performed a retrospective review of cancer associated CVT identified through an institutional data warehouse. The primary endpoint was radiological and comprised the evaluation of thrombus recanalization at 12 months. Secondary endpoints were clinical and included rates of bleeding complications and recurrence of CVT. Variables were compared across subgroups of study outcomes. The backward stepdown procedure was used to identify variables for the final logistic model regarding thrombosis and bleeding outcomes.

Results: The population included forty-five patients, slightly predominant of male adults (55.6\%) with a median age of 54.5 years. Solid malignancies comprised $64.4 \%$ of cases. A total of 33 cases were treated with anticoagulation. CVT recanalization was documented in almost $60 \%$ of cases. The cerebral venous thrombosis recurrence or propagation rate at 12 months was $15.6 \%$. Major bleeding complications were observed in 15 patients.

Conclusions: Our findings are suggestive of a narrow therapeutic index of anticoagulation in cancer-CVT. Careful monitoring of anticoagulation effect and bleeding complications are of utmost clinical relevance in cancer patients. Further larger and controlled studies are needed to confirm our observations.
\end{abstract}

Keywords: Cerebral, Thrombosis, Cancer, Anticoagulation

\footnotetext{
*Correspondence: cmrojas@mdanderson.org

A preliminary report of this study was presented in abstract form at the International Society of Thrombosis and Haemostasis Meeting, 2019 (Res

Pract Thromb Haemost, 3: 1-891.https://doi.org/10.1002/rth2.12229).

${ }^{4}$ Section of Benign Hematology, Department of Medicine, University of Texas M.D. Anderson Cancer Center, 1515 Holcombe Blvd. Suite 1464, TX, Houston, USA

Full list of author information is available at the end of the article
}

\section{$\triangle B M C$}

(c) The Author(s). 2021, corrected publication 2021. Open Access This article is licensed under a Creative Commons Attribution 4.0 International License, which permits use, sharing, adaptation, distribution and reproduction in any medium or format, as long as you give appropriate credit to the original author(s) and the source, provide a link to the Creative Commons licence, and indicate if changes were made. The images or other third party material in this article are included in the article's Creative Commons licence, unless indicated otherwise in a credit line to the material. If material is not included in the article's Creative Commons licence and your intended use is not permitted by statutory regulation or exceeds the permitted use, you will need to obtain permission directly from the copyright holder. To view a copy of this licence, visit http://creativecommons.org/ licenses/by/4.0/. The Creative Commons Public Domain Dedication waiver (http://creativecommons.org/publicdomain/zero/1. 0/) applies to the data made available in this article, unless otherwise stated in a credit line to the data. 


\section{Introduction}

Cerebral venous thrombosis (CVT) affects approximately five people per million annually and accounts for 0.5$1 \%$ of all cerebral thrombotic events [1]. Previously described risk factors include female gender, age $<40$, pregnancy, hormonal contraceptive use and thrombophilias [2]. It has been speculated that CVT could be more frequent in cancer patients due to a variety of mechanisms including direct tumor compression, cerebral sinus invasion, chemotherapeutic or hormonal agents $[3,4]$.

The exact incidence of CVT in cancer only population is unknown. Up to $30 \%$ of all first venous thromboembolic events are cancer associated and $7 \%$ of patients with CVT have a history of cancer at time of CVT diagnoses $[5,6]$. Studies assessing the association between CVT and recanalization rate, major bleeding or venous thrombosis reoccurrence in cancer only population have not been performed.
Our goal was to examine the clinical outcomes in cancer associated CVT, those included thrombus recanalization, cerebral venous thrombosis recurrence/propagation and bleeding rates.

\section{Methods}

We examined a retrospective cohort study of cancer patients with CVT identified through an institutional data warehouse at the University of Texas MD Anderson Cancer Center Hospital between January 2002 and June 2017.

Adult ( $\geq 18$ years) patients with active cancer or active cancer treatments and diagnosis of acute CVT were included. Patients with other indications for long term anticoagulation, chronic CVT, patients with acute CVT diagnosed at outside facility and not confirmed at our facility or those without documentation of clinical follow up 12 months after initial CVT event were excluded. (Fig. 1).

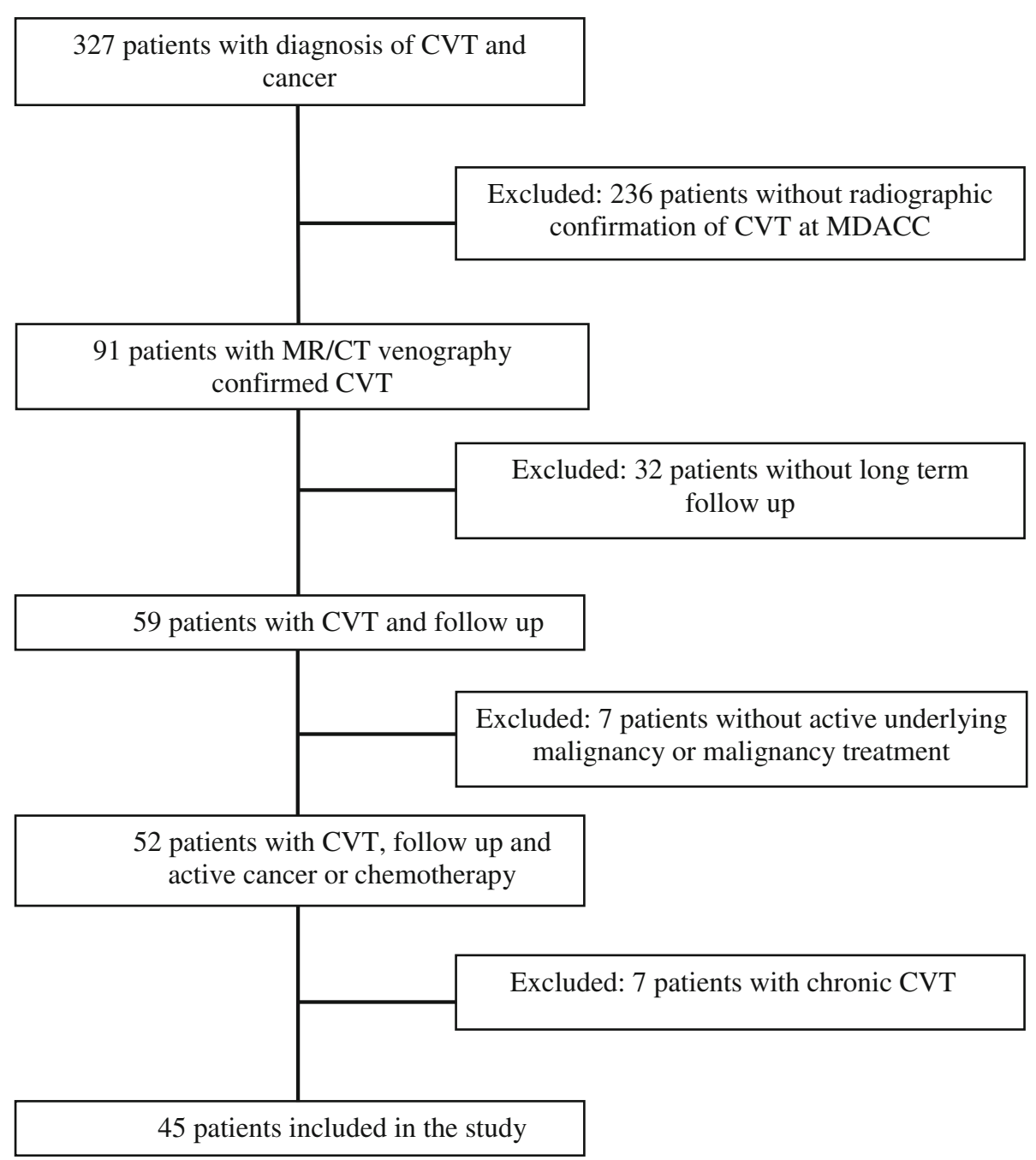

Fig. 1 Selection of cancer patients with acute cerebral venous thrombosis (CVT) 
Diagnosis of acute CVT was confirmed in all patients with computed tomographic-venography or magnetic resonance imaging with venography. This study was approved by the local ethics committee and institutional review board.

The primary endpoint was thrombus recanalization at 12 months, defined as partial (less than complete) or complete through the review and comparison of the diagnostic imaging data by an independent neuroradiologist.

Secondary endpoints were bleeding complications and CVT recurrence/propagation at 12 months. The outcome of bleeding was obtained from medical record review and defined by the World Health Organization bleeding scale [7].

Demographic data, major surgery, trauma, hormonal contraceptive use, cancer diagnosis and therapy were obtained at the time of CVT. CVT location and associated intracranial infarction or hemorrhage at time of initial diagnosis was recorded using imaging reports. Therapeutic medical antithrombotic treatment was recorded.

The distribution of each categorical variable was summarized in terms of its frequencies and percentages. Variables were compared across subgroups of study outcomes. The backward stepdown procedure was used to identify variables for the final logistic model regarding thrombosis and bleeding outcomes. Computations were carried out in SAS version 9.4.

\section{Results}

The population included 45 subjects, predominantly middle-aged adults and approximately half of them were overweight. Most of the patients had solid malignancies with locally advanced or distant metastatic disease (Table 1).

More than half of the cases had multifocal CVT and over one-third had concurrent intracranial hemorrhage at presentation (Table 1).

Anticoagulation was prescribed in $73.3 \%$ of cases, with a median duration of treatment of 7.9 months. Low molecular weight heparins (LMWH) were used in 23 cases, while 10 cases were treated with warfarin.

For the evaluation of the primary outcome, repeat vascular brain imaging for comparison was available in 41 patients. In those evaluable cases, partial thrombi recanalization was achieved in $36.6 \%$ of them, $95 \%$ CI [23.3, 51.8 ; and complete recanalization in $22.0 \%, 95 \% \mathrm{CI}$ $[11.5,36.2]$.

Although recanalization was more frequently seen in patients that received anticoagulation $(64.5 \%$ versus $40.0 \%$ ), there was not a statistical significant association between recanalization and the use of anticoagulation therapy $(p=.348)$.
Table 1 Baseline Demographic and Clinical and Radiological Characteristics at Cerebral Venous Thrombosis (CVT) presentation

\begin{tabular}{ll}
\hline Characteristic & $\mathbf{N}(\%)$ \\
\hline Male & $25(55.6 \%)$ \\
Age (years) Median, $[\mathrm{IQR}]$ & $54.5,[41.5,62.4]$ \\
Body Mass Index $\left(\mathrm{Kg} / \mathrm{m}^{2}\right)$ Median, $[\mathrm{IQR}]$ & $27.2,[23.4,33.4]$ \\
Malignancy type & \\
Hematologic & $15(33.3 \%)$ \\
Solid & $24(53.3 \%)$ \\
Primary CNS & $5(11.1 \%)$ \\
Concurrent solid and CNS & $1(2.2 \%)$ \\
Malignancy status & \\
Active & $32(71.1 \%)$ \\
Remission $<2$ years & $8(17.8 \%)$ \\
Remission $>2$ years & $4(8.9 \%)$ \\
Staging (AJCC) & \\
1 & $8(17.8 \%)$ \\
2 & $4(8.9 \%)$ \\
3 & $5(11.1 \%)$ \\
4 & $17(37.8 \%)$ \\
Active chemotherapy & $20(44.4 \%)$ \\
Hormonal cancer therapy & $4(8.9 \%)$ \\
Tyrosine kinase inhibitor & $1(2.2 \%)$ \\
Use of ESA & $1(2.2 \%)$ \\
Recent major surgery & $27(60.0 \%)$ \\
Multifocal CVT & $26(57.8 \%)$ \\
Occlusive CVT & $14(31.1 \%)$ \\
Concurrent brain venous infarction & $12(26.7 \%)$ \\
\hline & $16(35.6 \%)$ \\
\hline
\end{tabular}

Overall bleeding occurred in $46.7 \%$ of patients, $95 \%$ CI [32.7, 61.1]. A total of 15 patients suffered major bleeding defined as WHO grade 3 or 4 (Table 2).

Intracranial hemorrhage $(\mathrm{ICH})$ was the most common major bleeding complication. Of those patients, seven presented at diagnosis of CVT and the bleeding worsened ( 1 with subdural hematoma, 1 case with a subdural hygroma with new blood products, 2 cases of hemorrhagic tumor in the brain and 3 with other parenchymal bleeding). The remaining six cases had ICH de novo after CVT diagnosis ( 1 case ICH after fall, 1 case of brain tumor hemorrhage, 1 case in the setting of acute leukemia and 3 cases after central nervous system procedures).

The occurrence of ICH during treatment for CVT did not correlate with the presence of multifocal CVT ( $p=$ $.507)$, venous infarction at diagnosis $(p=1.000)$ or CVT recurrence $(p=1.000)$. 
Table 2 Bleeding Complications after Diagnosis of Cerebral Venous Thrombosis

\begin{tabular}{lll}
\hline Bleeding characteristics & $\mathbf{N}$ & $\%, \mathbf{9 5} \mathbf{C l}^{\mathbf{a}}$ \\
\hline $\begin{array}{l}\text { WHO grading of bleeding } \\
<3\end{array}$ & 6 & \\
3 & 1 & $28.5,[8.4,66.8]$ \\
4 & 14 & $4.8,[0.5,20.2]$ \\
Bleeding location ${ }^{\mathrm{b}}$ & & $66.7,[45.4,83.7]$ \\
Brain & 13 & \\
Skin & 4 & $61.9,[40.7,80.1]$ \\
Body cavity & 2 & $19.0,[6.8,39.2]$ \\
Nasal/oral mucosa & 2 & $9.5,[2.0,27.2]$ \\
Gastrointestinal tract & 1 & $9.5,[2.0,27.2]$ \\
\hline
\end{tabular}

${ }^{a}$ Estimates calculated over 21 total cases of bleeding

${ }^{\mathrm{b}}$ One patient presented with bleeding in the brain and other body location

The incidence of ICH after CVT diagnosis was higher in the anticoagulation group $(30.3 \%, 95 \mathrm{CI}[16.8,47.1])$ versus no anticoagulation $(25.0 \%, 95 \mathrm{CI}[7.6,52.9])$ with no significant statistical difference $(p=1.000)$.

When examining the bleeding outcomes by the treatment and patient-clinical characteristics, the choice anticoagulation agent was associated with those events. For LMWH, (8/23) $34.8 \%$ had any bleeding complications; for warfarin, (8/10) $80.0 \%$, (OR 7.50, 95 CI 1.0554.3, $p=.048$ ).

The overall rate of CVT recurrence was $15.6 \%, 95 \%$ CI $[7.2,28.1]$. The specific recurrent rates of not anticoagulated, LMWH- and warfarin-treated patients were (3/ 12) $25.0 \%$, (3/23) $13.0 \%$, and $(1 / 10) 10.0 \%$, respectively. Those differences were not statistically significant $(p=$ .362).

Since the total number of cases of CVT recurrence was small, further analyses for differences by clinical and treatment features were not performed.

\section{Discussion}

Current guidelines recommend initial CVT management with adjusted-dose unfractioned heparin (UFH) or weightbased dose of LMWH followed by vitamin $\mathrm{K}$ antagonists (VKA) [8-12]. However, those guidelines, and the clinical studies supporting them, lack of a sufficient number of cases with concurrent active malignancy to fully extrapolate those recommendations to cancer population.

Recently published results from a randomized clinical trial confirmed the efficacy and safety of long-term anticoagulation for CVT with oral anticoagulants (VKA or dabigatran) [13]. Evidence-based data to support the use of other oral anticoagulants is at this point less robust [14].

Our findings suggest that the risk of thrombotic and hemorrhagic complications are both high in cancer patients who suffer CVT. Those complications are well known to be prevalent in cancer population, so there is a narrow therapeutic index when anticoagulation treatments are instituted [15].

Studies in non-cancer CVT population have shown an association between the lack of venous recanalization and worsened clinical outcomes [16]. Sousa et al. showed that recanalization was associated with a 3.3-fold increase in the odds to complete functional recovery (95\% CI, 1.2-8.9) [17, 18]. In a meta-analysis of 818 non-cancer CVT cases, the recanalization rate was $85 \%$ (95\% CI, 80-89; $\mathrm{I}^{2}=58 \%$ ) in patients receiving anticoagulation [16]. Proposed mechanisms for those findings include prevention of propagation of CVT, restoration of anterograde drainage and salvage of brain tissue from permanent damage and reduction of risk of other venous thrombotic events. Our study showed a higher rate of CVT recanalization in patients who received anticoagulation compared with those who did not, however the difference was not statically significant. Due to the small absolute numbers of CVT recurrences and the retrospective design of the study, we could not perform further analyses to correlate with other clinical features.

The most remarkable finding in our study was the high rate of major bleeding complications, in particular $\mathrm{ICH}$. This differs from the lower frequency of $\mathrm{ICH}$ complications seen in anticoagulation clinical studies for cancer associated-thrombosis and in other non-cancer population CVT studies [19-22, 13, 18]. We hypothesize that the differences are explained by the provoked (trauma, intracranial tumor, invasive brain procedures, radiation) etiology in our cohort as opposed to anticoagulation only-related bleeding.

Additionally, our data showed that the risk of bleeding was independently increased during the use of warfarin when compared with LMWH. Other investigators have found associations suggesting that overweight population may require higher doses of warfarin to maintain a therapeutic international normalized ratio (INR) [23]. Others have also observed that an elevated body mass index predicts a higher incidence of bleeding during anticoagulation with warfarin [24]. We did not find a statistically differences in bleeding outcomes by the body mass index of the patients. Current guidelines recommend monitoring carefully using the INR in obese and non-obese patients [25-29]. In our study, data on INR and dosage of anticoagulants were not retrieved.

Limitations to our study are the retrospective design; therefore, we could not estimate the effect of anticoagulation monitoring, drug-to-drug interactions, appropriate dosing, and treatment compliance in our outcomes. Additionally, due to the small cohort, our observations are limited, yet suggestive of higher bleeding complications in CVT cancer-population, in particular in those treated with warfarin. 


\section{Conclusions}

Our findings are suggestive of a narrow therapeutic index of anticoagulation in cancer-CVT. Careful monitoring of anticoagulation complications are of utmost clinical relevance in cancer patients; in particular those with brain metastasis, invasive procedures, and treatment with warfarin. While our population is exclusively of cancer patients, larger and controlled studies are needed to confirm our observations in that population.

\section{Acknowledgements}

None.

\section{Authors' contributions}

N.I.A. designed the research and wrote the paper. W.Q. analyzed the data. N.G. provided the institutional data warehouse program. C.M.R. designed the research and edited the paper. All authors approved the final version of the manuscript.

\section{Funding}

None.

\section{Declaration}

\section{Competing interests}

Cristhiam Rojas-Hernandez

Daichii Sankyo, funding for research.

Naveen Garg

Consultant for Enlitic Inc. Owner Garglet LLC.

Nadia Abelhad has no COI to disclose.

Wei Qiao has no COI to disclose.

\section{Author details}

'Department of Medicine, University of Texas Health Science Center at Houston, Houston, USA. ${ }^{2}$ Department of Biostatistics, University of Texas M.D. Anderson Cancer Center, Houston, USA. ${ }^{3}$ Department of Diagnostic Radiology, Division of Diagnostic Imaging, University of Texas M.D. Anderson Cancer Center, Houston, USA. ${ }^{4}$ Section of Benign Hematology, Department of Medicine, University of Texas M.D. Anderson Cancer Center, 1515 Holcombe Blvd. Suite 1464, TX, Houston, USA.

Received: 3 November 2020 Accepted: 17 May 2021

Published online: 01 June 2021

\section{References}

1. Bousser MG, Ferro JM. Cerebral venous thrombosis: an update. Lancet Neurol. 2007;6(2):162-70. https://doi.org/10.1016/S1474-4422(07)70029-7.

2. Stam J. Thrombosis of the cerebral veins and sinuses. N Engl J Med. 2005; 352(17):1791-8. https://doi.org/10.1056/NEJMra042354.

3. Rogers LR. Cerebrovascular complications in patients with cancer. Semin Neurol. 2004;24(4):453-60. https://doi.org/10.1055/s-2004-861539.

4. Raizer JJ, DeAngelis LM. Cerebral sinus thrombosis diagnosed by MRI and MR venography in cancer patients. Neurology. 2000;54(6):1222-6. https:// doi.org/10.1212/wnl.54.6.1222.

5. Braekkan SK, Borch KH, Mathiesen EB, Njolstad I, Wilsgaard T, Hansen JB. Body height and risk of venous thromboembolism: The Tromso Study. Am J Epidemiol. 2010;171(10):1109-15. https://doi.org/10.1093/aje/kwq066.

6. Ferro JM, Canhao P, Stam J, Bousser MG, Barinagarrementeria F, Investigators I. Prognosis of cerebral vein and dural sinus thrombosis: results of the International Study on Cerebral Vein and Dural Sinus Thrombosis (ISCVT). Stroke. 2004;35(3):664-70. https://doi.org/10.1161/01.STR.000011 7571.76197 .26

7. Miller $A B$, Hoogstraten $B$, Staquet $M$, Winkler $A$. Reporting results of cancer treatment. Cancer. 1981:47(1):207-14. https://doi.org/10.1002/1097-0142 (19810101)47:1<207::aid-cncr2820470134>3.0.co;2-6.

8. Saposnik G, Barinagarrementeria F, Brown RD Jr, Bushnell CD, Cucchiara B, Cushman M, deVeber G, Ferro JM, Tsai FY, American Heart Association Stroke $C$, the Council on $E$, Prevention. Diagnosis and management of cerebral venous thrombosis: a statement for healthcare professionals from the American Heart Association/American Stroke Association. Stroke. 2011 42(4):1158-92. https://doi.org/10.1161/STR.0b013e31820a8364.

9. Ferro JM, Bousser M-G, Canhão P, Coutinho JM, Crassard I, Dentali F, di Minno M, Maino A, Martinelli I, Masuhr F. European Stroke Organization guideline for the diagnosis and treatment of cerebral venous thrombosisendorsed by the European Academy of Neurology. Eur Stroke J. 2017;2(3): 195-221.

10. Piazza G. Cerebral venous thrombosis. Circulation. 2012;125(13):1704-9.

11. Einhäupl K, Stam J, Bousser MG, De Bruijn S, Ferro J, Martinelli I, Masuhr F. EFNS guideline on the treatment of cerebral venous and sinus thrombosis in adult patients. Eur J Neurol. 2010;17(10):1229-35.

12. Lee S-K, Mokin M, Hetts SW, Fifi JT, Bousser M-G, Fraser JF. Current endovascular strategies for cerebral venous thrombosis: report of the SNIS Standards and Guidelines Committee. J Neurointerven Surg. 2018;10(8):803-10.

13. Ferro JM, Coutinho JM, Dentali F, Kobayashi A, Alasheev A, Canhao P, Karpov D, Nagel S, Posthuma L, Roriz JM, Caria J, Frassdorf M, Huisman H, Reilly P, Diener HC, Group R-SCS. Safety and Efficacy of Dabigatran Etexilate vs Dose-Adjusted Warfarin in Patients With Cerebral Venous Thrombosis: A Randomized Clinical Trial. JAMA Neurol. 2019. https://doi.org/10.1001/jama neurol.2019.2764.

14. Rao SK, Ibrahim M, Hanni CM, Suchdev K, Parker D, Rajamani K, Mohamed W. Apixaban for the treatment of cerebral venous thrombosis: a case series. J Neurol Sci. 2017;381:318-20.

15. Posch F, Konigsbrugge O, Zielinski C, Pabinger I, Ay C. Treatment of venous thromboembolism in patients with cancer: A network meta-analysis comparing efficacy and safety of anticoagulants. Thromb Res. 2015;136(3): 582-9. https://doi.org/10.1016/j.thromres.2015.07.011.

16. Aguiar de Sousa D, Lucas Neto L, Canhao P, Ferro JM. Recanalization in Cerebral Venous Thrombosis. Stroke. 2018;49(8):1828-35. https://doi.org/1 $0.1161 /$ STROKEAHA.118.022129.

17. Aguiar de Sousa D, Lucas Neto L, Arauz A, Sousa AL, Gabriel D, Correia M, Gil-Gouveia R, Penas S, Carvalho Dias M, Correia MA, Carvalho M, Canhao P, Ferro JM. Early Recanalization in Patients With Cerebral Venous Thrombosis Treated With Anticoagulation. Stroke. 2020;51(4):1174-81. https://doi.org/1 0.1161/STROKEAHA.119.028532

18. Dentali F, Gianni M, Crowther MA, Ageno W. Natural history of cerebral vein thrombosis: a systematic review. Blood. 2006;108(4):1129-34. https://doi. org/10.1182/blood-2005-12-4795.

19. Rojas-Hernandez CM, Oo TH, Garcia-Perdomo HA. Risk of intracranial hemorrhage associated with therapeutic anticoagulation for venous thromboembolism in cancer patients: a systematic review and metaanalysis. J Thromb Thrombolysis. 2017;43(2):233-40. https://doi.org/10.1007/ s11239-016-1434-4.

20. Kraaijpoel N, Di Nisio M, Mulder Fl, van Es N, Beyer-Westendorf J, Carrier M, Garcia D, Grosso M, Kakkar AK, Mercuri MF, Middeldorp S, Hernandez CR, Santamaria A, Schwocho L, Segers A, Verhamme P, Wang TF, Weitz JI, Zhang G, Zwicker Jl, Buller HR, Raskob GE. Clinical Impact of Bleeding in Cancer-Associated Venous Thromboembolism: Results from the Hokusai VTE Cancer Study. Thromb Haemost. 2018;118(8):1439-49. https://doi.org/10.1 055/s-0038-1667001

21. Young AM, Marshall A, Thirlwall J, Chapman O, Lokare A, Hill C, Hale D, Dunn JA, Lyman GH, Hutchinson C. Comparison of an oral factor Xa inhibitor with low molecular weight heparin in patients with cancer with venous thromboembolism: results of a randomized trial (SELECT-D). J Clin Oncol. 2018.

22. Agnelli G, Becattini C, Meyer G, Munoz A, Huisman MV, Connors JM, Cohen A, Bauersachs R, Brenner B, Torbicki A, Sueiro MR, Lambert C, Gussoni G, Campanini M, Fontanella A, Vescovo G, Verso M, Caravaggio I. Apixaban for the Treatment of Venous Thromboembolism Associated with Cancer. N Engl J Med. 2020. https://doi.org/10.1056/NEJMoa1915103.

23. Mueller JA, Patel T, Halawa A, Dumitrascu A, Dawson NL. Warfarin dosing and body mass index. Ann Pharmacother. 2014;48(5):584-8. https://doi. org/10.1177/1060028013517541.

24. Ogunsua AA, Touray S, Lui JK, Ip T, Escobar JV, Gore J. Body mass index predicts major bleeding risks in patients on warfarin. J Thromb Thrombolysis. 2015;40(4):494-8. https://doi.org/10.1007/s11239-015-1226-2.

25. Kearon C, Akl EA, Ornelas J, Blaivas A, Jimenez D, Bounameaux H, Huisman M, King CS, Morris TA, Sood N. Antithrombotic therapy for VTE disease: CHEST guideline and expert panel report. Chest. 2016;149(2):315-52.

26. Thein KZ, Oo TH. 2019 international clinical practice guidelines for the treatment of venous thromboembolism. Lancet Oncol. 2019;20(12):e655 https://doi.org/10.1016/S1470-2045(19)30734-X. 
27. Witt DM, Nieuwlaat R, Clark NP, Ansell J, Holbrook A, Skov J, Shehab N, Mock J, Myers T, Dentali F, Crowther MA, Agarwal A, Bhatt M, Khatib R, Riva JJ, Zhang Y, Guyatt G. American Society of Hematology 2018 guidelines for management of venous thromboembolism: optimal management of anticoagulation therapy. Blood Adv. 2018;2(22):3257-91. https://doi.org/1 $0.1182 /$ bloodadvances.2018024893.

28. Key NS, Khorana AA, Kuderer NM, Bohlke K, Lee AYY, Arcelus JI, Wong SL, Balaban EP, Flowers CR, Francis CW, Gates LE, Kakkar AK, Levine MN, Liebman HA, Tempero MA, Lyman GH, Falanga A. Venous Thromboembolism Prophylaxis and Treatment in Patients With Cancer: ASCO Clinical Practice Guideline Update. J Clin Oncol. 2020;38(5):496-520. https://doi.org/10.1200/JCO.19.01461.

29. Farge D, Frere C, Connors JM, Ay C, Khorana AA, Munoz A, Brenner B, Kakkar A, Rafii H, Solymoss S, Brilhante D, Monreal M, Bounameaux H, Pabinger I, Douketis J. International Initiative on T, Cancer advisory p. 2019 international clinical practice guidelines for the treatment and prophylaxis of venous thromboembolism in patients with cancer. Lancet Oncol. 2019;20(10):e566e581. https://doi.org/10.1016/S1470-2045(19)30336-5.

\section{Publisher's Note}

Springer Nature remains neutral with regard to jurisdictional claims in published maps and institutional affiliations.

Ready to submit your research? Choose BMC and benefit from:

- fast, convenient online submission

- thorough peer review by experienced researchers in your field

- rapid publication on acceptance

- support for research data, including large and complex data types

- gold Open Access which fosters wider collaboration and increased citations

- maximum visibility for your research: over $100 \mathrm{M}$ website views per year

At BMC, research is always in progress.

Learn more biomedcentral.com/submissions 